\title{
Techno-Economic Analysis in the Production of Copper Nanoparticles by Biosynthetic Method using Citrus medica Linn. Extract
}

\author{
L S Anggiat ${ }^{*}$, R A Fadhilah'1, F K Insan'1, G C S Girsang1', A B D Nandiyanto ${ }^{1}$ \\ 1Departemen Pendidikan Kimia, Fakultas Pendidikan Matematika dan Ilmu Pengetahuan \\ Alam, Universitas Pendidikan Indonesia, Jl. Dr. Setiabudi no. 229, Bandung 40154, Jawa Barat, \\ Indonesia \\ Email: *lewi@upi.edu
}

\begin{abstract}
Copper nanoparticles are the most frequently used materials in the field of nanoscience because of their electrical, optical, biomedical, antifungal, and antibacterial properties. The synthesis of copper nanoparticles with biological methods is known to be environmentally friendly, inexpensive, simple, and capable of producing better nanoparticles than other methods. This study aims to determine the feasibility of an industrial project to manufacture $\mathrm{Cu}$ nanoparticles through a biosynthetic method using Citrus medica Linn. extract and evaluate it from an engineering and economic point of view. Some of the parameters used for economic evaluation are Payback Period (PBP), Break Even Point (BEP), and Cumulative Net Present Value (CNPV). The analysis is supported using data taken from online shopping websites. The results showed that the number of $\mathrm{Cu}$ nanoparticles that could be produced in one year was $24,000 \mathrm{~kg}$. The total initial capital cost is $272,640.00 \mathrm{USD}$ and the profit is $698,655.90$ USD/year. PBP occurred in the 3rd year with the $\mathrm{CNPV} / \mathrm{TIC}$ value reaching $3.746 \%$ in the 9th year. Based on the economic evaluation, the project is concluded to be feasible to run with the anticipated tax and percentage of sales. The results of this study are expected to provide an overview of the economic evaluation of industrial-scale $\mathrm{Cu}$ nanoparticles production by biosynthetic method using Citrus medica Linn. extract.
\end{abstract}

\section{Introduction}

Copper nanoparticles are the most frequently used materials in the field of nanoscience because of their electrical, optical, biomedical, antifungal, and antibacterial properties [1], [2]. In addition, copper nanoparticles can be used as an alternative to gold and silver nanoparticles in the industrial sector because they are relatively cheaper [3]-[5]. Moreover, copper has advantages in green-nano preparations [6].

Several methods have been developed to synthesize copper nanoparticles including electrochemical [7], chemical reduction [8], thermal decomposition [9], microemulsion [10], photochemistry [11], laser ablation [12], gas evaporation [13], and biological methods [14]. In general, the methods currently most widely used is the chemical method because the method 
is simple and capable of producing high-quality nanoparticles [15]. However, chemical methods can't evade the use of hazardous chemicals [14], [16]. The method that is considered as the most appropriate for industrial scale and economic evaluation analysis is the biosynthetic method using Citrus medica Linn. extract. This method was chosen because it is environmentally friendly, inexpensive, simple, and produces very good nanoparticles.

The purpose of this paper is to determine the feasibility of the industrial project of making $\mathrm{Cu}$ nanoparticles through the biosynthetic method using Citrus medica Linn. extract and evaluate it from an engineering and economic point of view. This paper was created because there are not many papers published and discusses in detail the economic evaluation of the synthesis of $\mathrm{Cu}$ nanoparticles using the biosynthetic method using Citrus medica Linn. extract on an industrial scale. Several economic variations are determined, namely taxes, sales, raw materials, labor, and utilities. The results of this study are expected to provide an overview of the economic evaluation of industrial-scale $\mathrm{Cu}$ nanoparticles production by biosynthetic method using Citrus medica Linn. extract.

\section{Method}

\subsection{Theory of $\mathrm{Cu}$ Nanoparticles Synthesis}

Biological methods have been chosen as an alternative to synthesize $\mathrm{Cu}$ nanoparticles which is simple and environmentally friendly. $\mathrm{Cu}$ nanoparticles can be synthesized by utilizing Citrus medica Linn. fruit extract [1]. Citrus medica Linn. extract preparation can be done by squeezing clean and fresh fruit, then the juice is filtered using a muslin cloth and filter paper. The biomolecules contained in Citrus medica Linn. extract are used as a reducing agent and self-stabilizer for $\mathrm{Cu}$ nanoparticles. The synthesis method was initiated by reacting $100 \mathrm{~mL}$ of $1 \mathrm{mM} \mathrm{CuSO}_{4} \cdot 5 \mathrm{H}_{2} \mathrm{O}$ with $10 \mathrm{~mL}$ of Citrus medica Linn. extract. The reaction mixture was stirred at $60^{\circ} \mathrm{C}$ for 1 hour. The color change will occur slowly from light blue to reddish brown. The $\mathrm{Cu}$ precipitate formed was centrifuged at $4000 \mathrm{rpm}$ for 30 minutes. The copper nanoparticles were washed with distilled water and dried in an oven at $80^{\circ} \mathrm{C}$. The diagram process of synthesis of copper nanoparticles are presented. (See Figure 1).

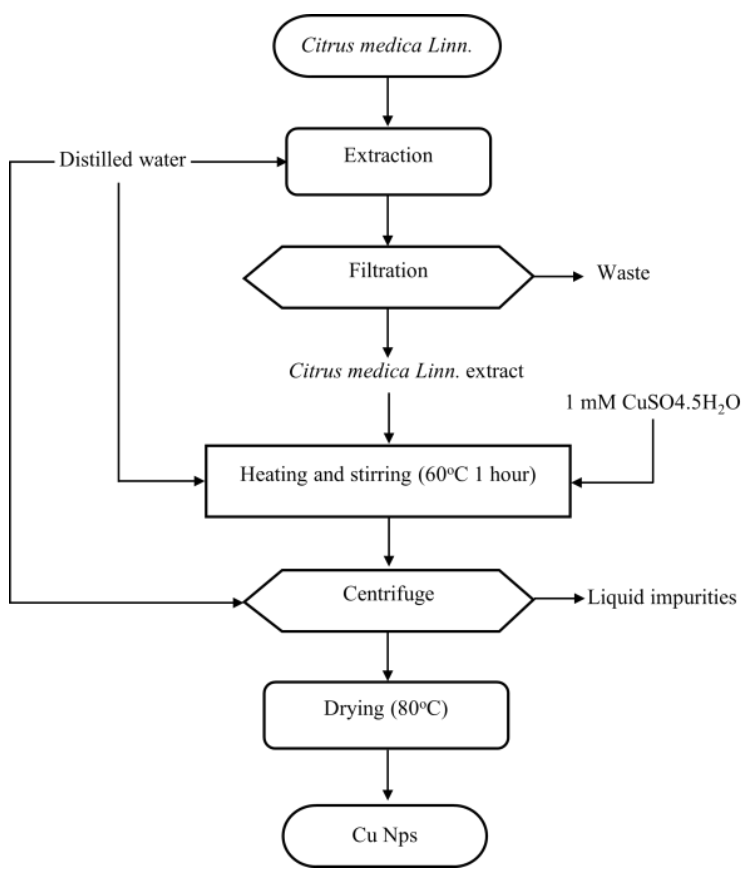




\section{International Journal of Research and Applied Technology}

1(1)(2021) 200-210

Journal homepage: https://ojs.unikom.ac.id/index.php/injuratech

Figure 1. Synthesis of copper nanoparticles using Citrus medica Linn. extract

\subsection{Economic Evaluation}

The economic analysis in this study is based on an analysis of the prices of materials, equipment, and equipment specifications available on online shopping sites. The data is calculated based on mathematical calculations to obtain economic parameters such as GPM, PBP, BEP, CNPV, and PI. These economic parameters are calculated based on the formula below [17].

1. Gross profit margin (GPM) is calculated by subtracting the price of raw materials from the selling price.

2. Payback period (PBP) is a calculation to predict the length of time required for an investment to be able to return the total initial expenditure. In short, PBP is set when the CNPV/TIC reaches zero for the first time.

3. Break even point (BEP) is the minimum amount of product that must be sold at a certain price to cover the total cost of production.

4. Cumulative net present value (CNPV) is a value that predicts the condition of a production project in the form of a production function in several years. CNPV is a value that expresses the expenses and income of a business.

5. Profitability Index (PI) is an index used to identify the relationship between project costs and impacts. PI can be calculated by dividing the CNPV by the total investment cost (TIC). If the PI is less than one, then the project can be classified as an unprofitable project and if the PI is more than one then the project can be classified as a good/profitable project.

These data are calculated to determine the economic feasibility of the copper nanoparticle synthesis project using this method. When evaluating economic viability, various conditions are tested such as changes in raw material prices, sales capacity, utilities, employee salaries, and external conditions.

Various assumptions in the industrial-scale synthesis of $\mathrm{Cu}$ nanoparticles are based on stoichiometric and mass balance calculations. The assumptions were: (1) All materials used in the synthesis of $\mathrm{Cu}$ nanoparticles such as copper (II) sulfate pentahydrate $\left(\mathrm{CuSO}_{4} \cdot 5 \mathrm{H}_{2} \mathrm{O}\right)$, Citrus medica Linn. fruit extract, and distilled water were magnified 1500 times calculated based on the literature. (2) Copper(II) sulfate pentahydrate $\left(\mathrm{CuSO}_{4} .5 \mathrm{H}_{2} \mathrm{O}\right)$ and Citrus medica Linn. extract react in a 10:1 ratio. (3) The percentage of nanoparticle formation process is $100 \%$.

Several assumptions are used to support the calculation of the economic evaluation. In this study, some of the assumptions used are as follows.

1. Calculation is based on conversion of $1 \mathrm{USD}=15,000 \mathrm{IDR}$;

2. Based on commercially available prices, the prices of $\mathrm{CuSO}_{4} \cdot 5 \mathrm{H}_{2} \mathrm{O}$ and Citrus medica Linn. fruit in $\mathrm{kg}$ are $2.00 \mathrm{USD} / \mathrm{kg}$ and $0.53 \mathrm{USD} / \mathrm{kg}$, respectively. Distilled water is obtained from treated water treatment at the factory, assuming the location of the factory is located near natural water sources. All materials are calculated based on stoichiometric calculations;

3. Total investment cost (TIC) is calculated based on the Lang Factor;

4. The process of making copper nanoparticles in one process is assumed to take about 4 hours;

5. The number of $\mathrm{Cu}$ nanoparticles obtained in one production is $8 \mathrm{~kg}$;

6. Cu nanoparticles are priced at $50 \mathrm{USD} / \mathrm{kg}$; 


\section{International Journal of Research and Applied Technology}

1(1)(2021) 200-210

Journal homepage: https://ojs.unikom.ac.id/index.php/injuratech

7. The project runs for 5 working days a week for a total of 240 days a year;

8. Utilities are simplified by describing and converting it to electrical units, such as $\mathrm{kWh}$;

9. The total salary of workers is $75,000 \mathrm{USD} /$ year;

10. Discount rate of $15 \%$ per year [18];

11. $10 \%$ income tax [18];

12. The project will operate for 9 years.

The process of making $\mathrm{Cu}$ nanoparticles using a biosynthetic method using Citrus medica Linn. extract calculated using various economic evaluation parameters. The calculation results obtained from standard assumptions are called economic evaluations under ideal conditions. Furthermore, economic evaluation is carried out by varying external conditions, percentage of sales, and variable costs to evaluate the feasibility of the project.

\section{Results and Discussion}

\subsection{Engineering Perspective}

Figure 2 shows the manufacturing process of $\mathrm{Cu}$ nanoparticles using the biosynthetic method by Citrus medica Linn. based on the literature [1]. From an engineering point of view, the synthesis of $\mathrm{Cu}$ nanoparticles using this method can be carried out on an industrial scale. The total cost of raw materials in one year is 272,640.00 USD. This cost is required to produce $\mathrm{Cu}$ nanoparticles as much as $\pm 24,000 \mathrm{~kg} /$ year. Sales in one year resulted in a profit of $698,655.90$ USD. The cost for purchase of equipment is 99,210 USD. The project life span is 9 years, producing $\mathrm{Cu}$ nanoparticles with $\mathrm{CNPV} / \mathrm{TIC}$ reaching $3.746 \%$ of the total revenue in 9 years. The PBP in this project was achieved in the 3rd year.

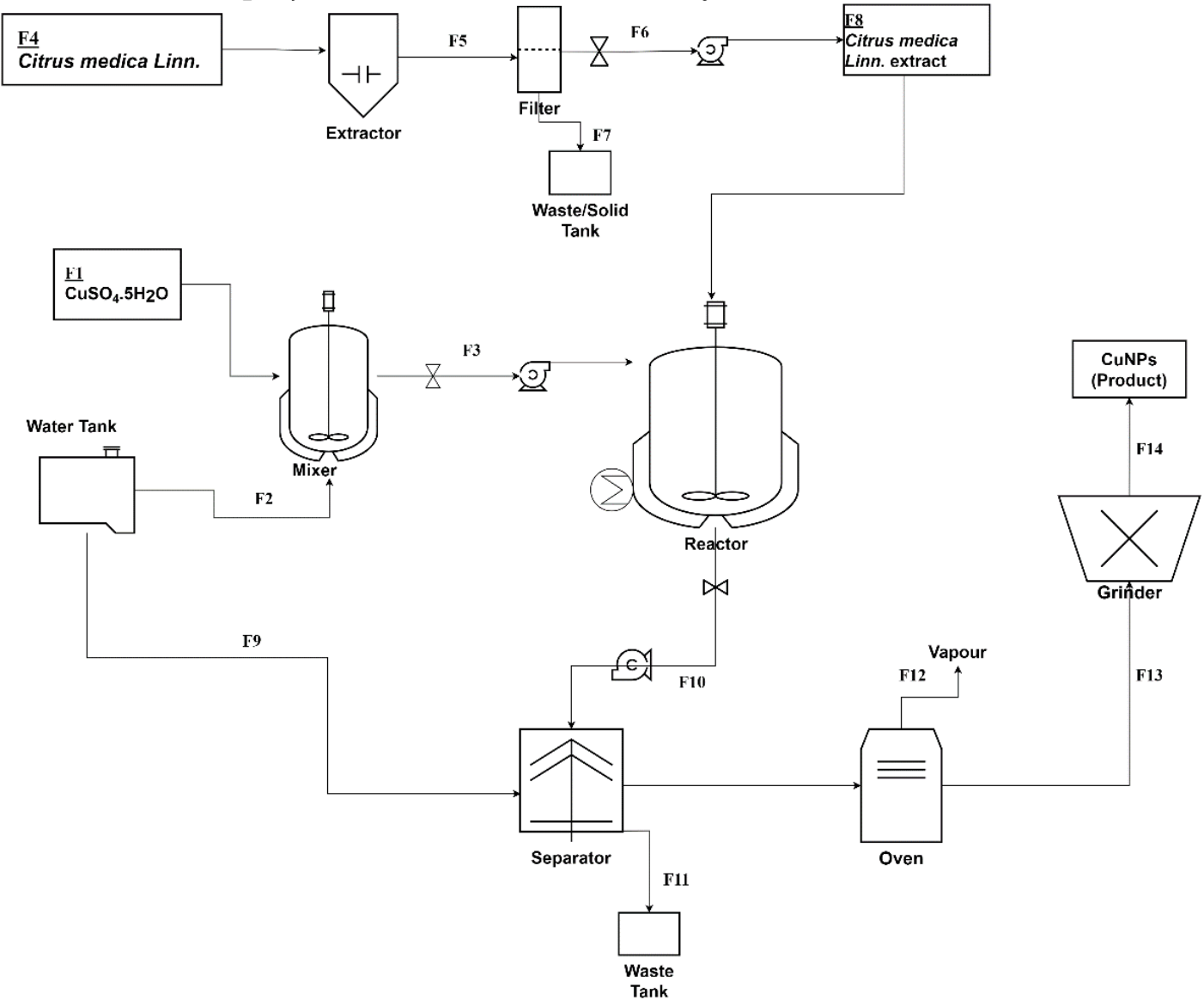




\section{International Journal of Research and Applied Technology}

1(1)(2021) 200-210

Journal homepage: https://ojs.unikom.ac.id/index.php/injuratech

Figure 2. Process Flow Diagram of $\mathrm{Cu}$ nanoparticle synthesis

\subsection{Economic Evaluation}

\subsubsection{Ideal Conditions}

The relationship between the value of CNPV/TIC (\%) and the project life (years) under ideal conditions is shown in Figure 3. In the graph, the y-axis is CNPV/TIC (\%) and the $x$ axis is the project life (years). The curve shows that the CNPV/TIC value is negative or below zero until the third year. The existence of CNPV/TIC values below zero is due to the initial capital cost to produce $\mathrm{Cu}$ nanoparticles. The initial capital costs include the cost of purchasing land, equipment, and building construction. The initial capital cost returns when the payback period (PBP) occurs, which is when the curve rises again and hits zero. The payback period in this project occurs in the third year, as shown in Figure 3. After the 3rd year, the income keeps increasing every year. The lowest CNPV/TIC value occurred in the 2nd year with a value of $-0.845 \%$. While the highest value occurred in the 9th year with a value of $3.746 \%$. A project can be said to be profitable if the CNPV/TIC or PI value is more than 1 . Thus, the production of $\mathrm{Cu}$ nanoparticles can be considered a profitable project because it requires a short time to recover investment costs and has a PI value of more than 1 .

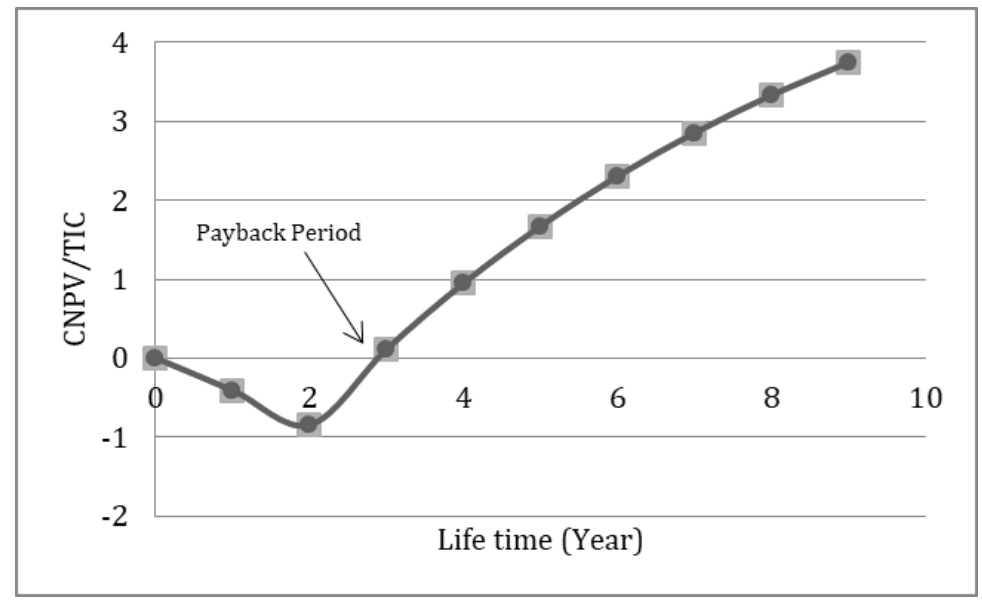

Figure 3. CNPV graph under ideal conditions

\subsubsection{Impact of External Conditions}

Tax is one of the external factors of a project that can affect revenue. Taxes come from the state that finances public spending. The CNPV/TIC curve in the $\mathrm{Cu}$ nanoparticle synthesis project is made in various tax variations and is presented in Figure 4 . In the graph, the y-axis is CNPV/TIC (\%) and the $x$-axis is the project life (years).

The amount of tax variation used for the economic evaluation of this project is $10,25,50$, 75 , and $100 \%$ of the total revenue. In the first to second years, the curve goes down and is negative. This is because in that year, the project did not benefit from the cost of purchasing land, equipment and building construction. In the 2nd year onwards, the curve starts to increase. The tax is valid for 2 years after the project is running. The amount of tax affects the level of income increase. Increasing taxes will result in lower profits.

The amount of tax also affects the time of return of initial capital or payback period (PBP). Increasing taxes will result in a PBP that is longer than ideal conditions. According to the CNPV/TIC graph shown in Figure 4, the 10\% and 25\% tax variation causes PBP to occur in year 3; $50 \%$ tax variation causes PBP to occur in the 3.5 th year; $75 \%$ tax variation causes PBP to occur in the 4.5 th year; and the $100 \%$ tax variation causes the project to not reach the PBP 

the total income. If the tax received is more than $75 \%$, the project will fail.

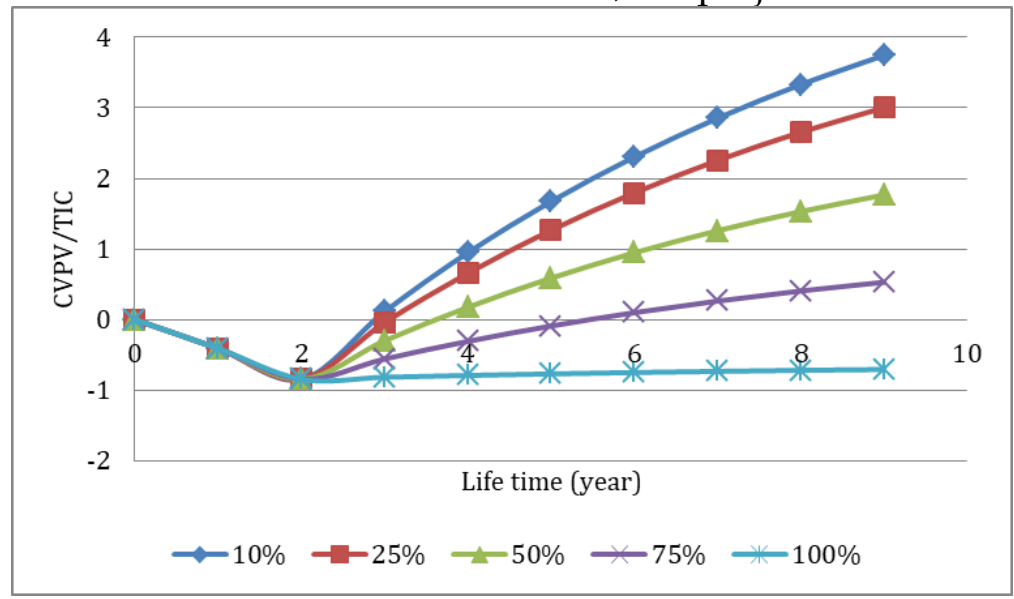

Figure 4. Graph of CNPV on tax variations

\subsubsection{Changes in Sales}

Figure 5 shows a graph of CNPV/TIC for 9 years on the percentage variation of total sales. Economic evaluation of the percentage of total sales is done by changing the number of sales to $80,60,40$, and $20 \%$. The $100 \%$ sales percentage curve is a curve under ideal conditions. According to the CNPV/TIC graph presented in Figure 5, a decrease in the level of sales (\%) will result in lower profit income than ideal conditions.

In the first to second years, the CNPV/TIC value falls below zero or is negative. The decrease was due to the project being still under construction, so that the production and sale of $\mathrm{Cu}$ nanoparticle products could not yet be carried out. After the second year, the change in the value of CNPV/TIC depends on the amount of sales (\%). This percentage of sales also affects the length of time for the recovery of the initial capital cost or payback period (PBP).

Based on PBP analysis, sales variation under normal conditions causes PBP to occur in the 3rd year; $80 \%$ sales variation causes PBP to occur in the 3,25th year; $60 \%$ sales variation causes PBP to occur in the 6th year; and sales variations of 20 to $40 \%$ cause the project to not reach PBP even in the 9th year of the project's life. Therefore, the percentage of product sales should not be less than $60 \%$. From this economic evaluation chart, the percentage of sales is very influential on the success of a project. If the sales percentage is only $60 \%$ or below, the project will fail.

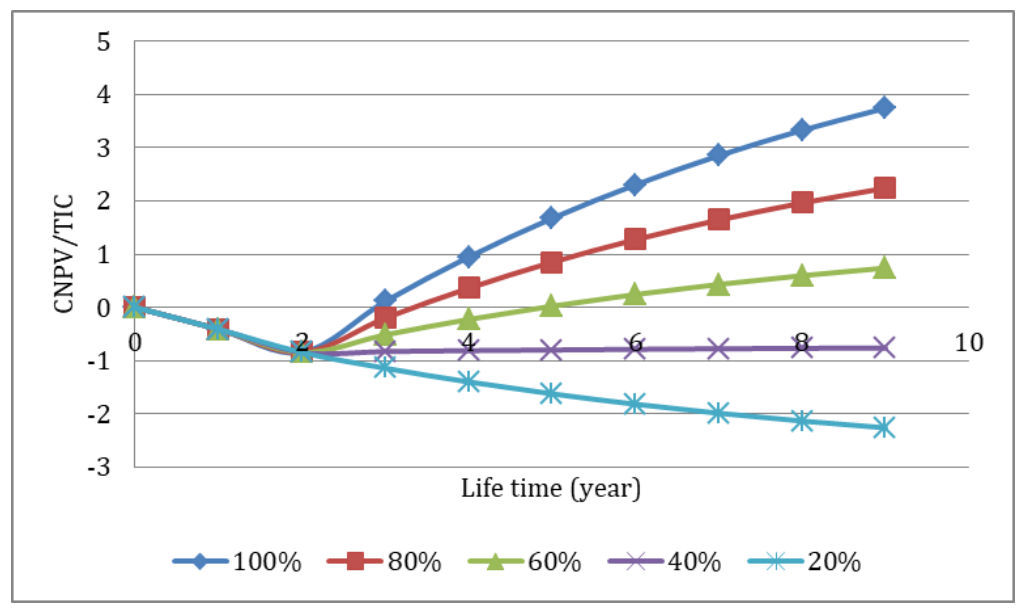




\subsubsection{Changes in Variable Cost (Raw Materials, Labor, Utilities)}

Labor, raw material prices, and utilities are factors that can affect the success of a project. Figure 6 shows a graph of CNPV for 9 years with fluctuations obtained from variations in raw material prices. Fluctuations in the price of raw materials were analyzed by varying the price of raw materials by $75,125,150$, and $200 \%$ from the normal price $(100 \%)$. The graph of fluctuations in the price of raw materials can be compared with the diagram under ideal (normal) conditions.

The effect of variations in raw material prices is seen after the project has been running for 2 years. Changes in the price of raw materials cause changes in the level of income from ideal conditions. The value of CNPV/TIC in the 9th year with variations in raw material prices of $75,100,125,150$, and $200 \%$ is $4.204 ; 3,746 ; 3,288 ; 2,829$; and 1,911 . Changes in raw material prices also affect the length of time for recovery of initial capital costs or payback period (PBP). PBP results from variations in raw material prices of $75,100,125,150$, and $200 \%$ are achieved in the 2nd to 4 th years. The amount of raw material prices has an effect on the recovery time of capital which is longer than ideal conditions. However, with variations in raw material prices, the CNPV/TIC value is still above 1 in all variations. Thus, this project will be successful even though the raw material price is $200 \%$ of the normal price $(100 \%)$.

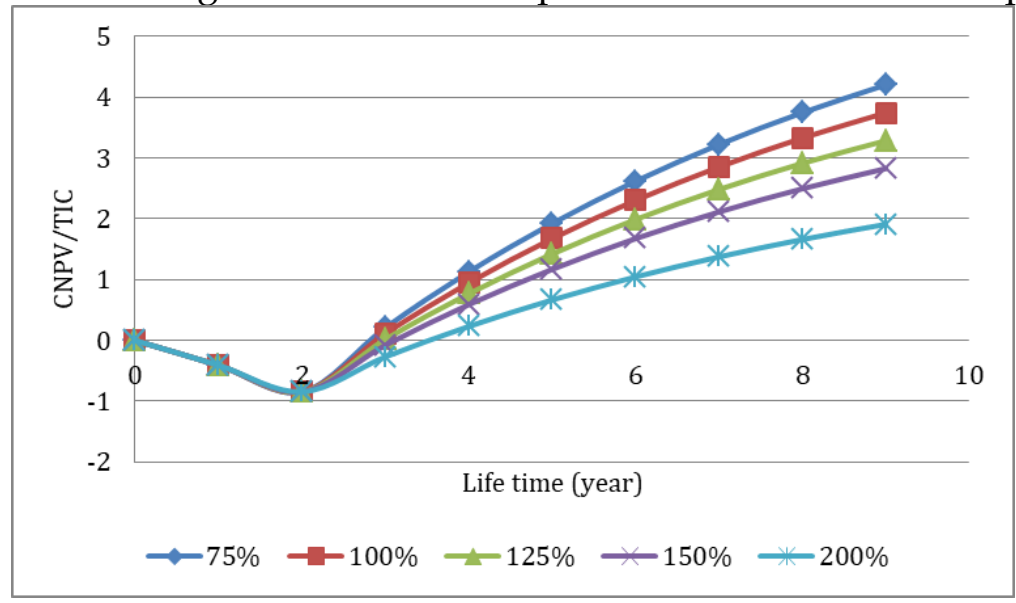

Figure 6. CNPV graph on variations in raw material prices

Figure 7 shows a graph of CNPV for 9 years with fluctuations derived from utility variations. Analysis of utility variation is done by varying the utility costs by $75,120,150$, and $200 \%$ of normal costs $(100 \%)$. The graph of utility price fluctuations is compared to the graph under ideal (normal) conditions.

Based on the graph presented in Figure 7, the decrease and increase in utility costs did not result in a significant change in the value of CNPV/TIC. The value of CNPV/TIC in the 9th year for variations in utility costs of $75,100,125,150$, and $200 \%$ is around 3.74 . The curves for all variations of utility costs appear to coincide. This shows that changes in utility costs do not have much effect even though utility costs are $200 \%$ of normal costs. Thus, this project is considered profitable because the CNPV/TIC value is more than 1 for all ranges of utility cost variations. 


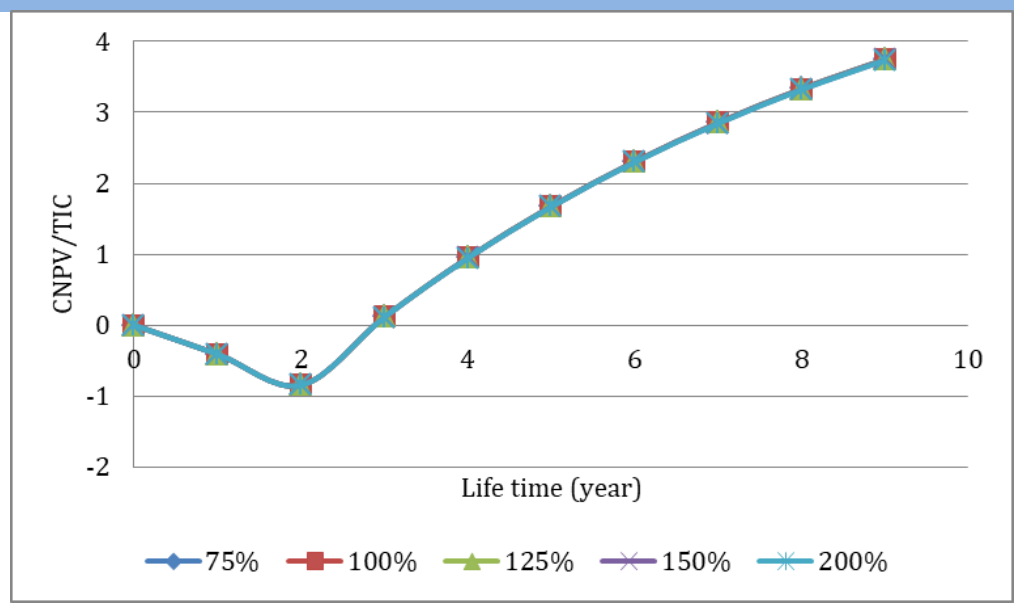

Figure 7. Graph of CNPV on utility cost variations

Figure 8 shows a graph of CNPV for 9 years with fluctuations obtained from variations in the increase in labor wages. The analysis of labor wage variations was carried out by varying the wages of workers by 120,140,150,160, 180 and 200\% from normal conditions. The variation graph is then compared with the graph under ideal conditions or when the labor wage is $100 \%$.

Changes in labor wages that are greater than ideal conditions result in lower profit income. The value of CNPV/TIC in the 9th year for variations in the increase in labor wages of $100,120,140,160,180$, and $200 \%$ is 3,$746 ; 3,578 ; 3,409 ; 3,240 ; 3,072$; and 2,903 . PBP results from all variations in labor wages are achieved in years 2 to 3 . Thus, this project will still be successful even though the wages of workers are $200 \%$ of the ideal condition.

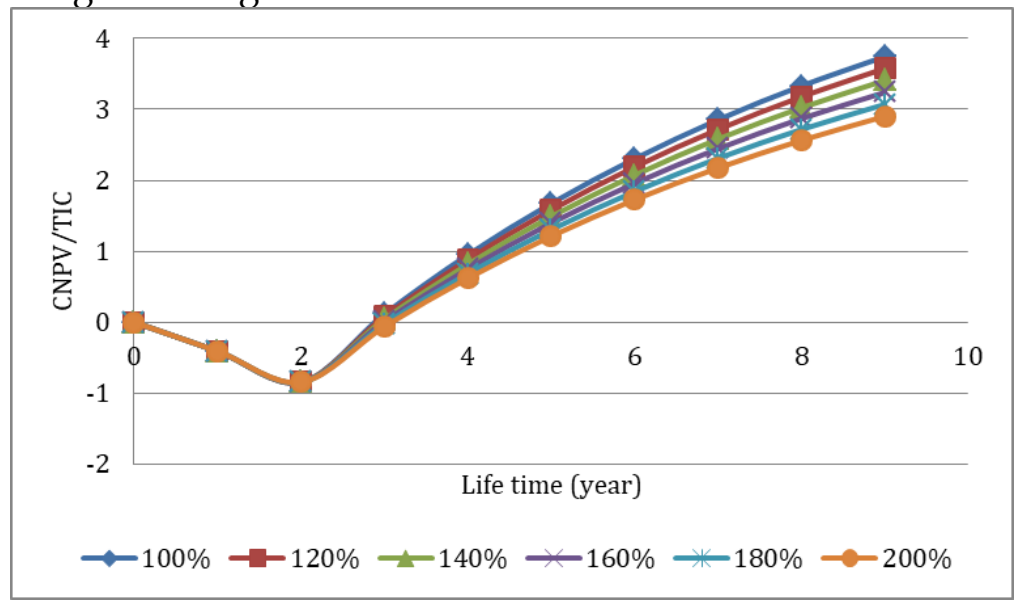

Figure 8. Graph of CNPV with worker's salary variation

\section{Conclusion}

Based on the analysis that has been carried out, the project for the production of $\mathrm{Cu}$ nanoparticles by the biosynthetic method by Citrus medica Linn. quite promising when assessed from an economic and technical point of view. This project can compete with PBP capital market standards due to the short initial investment recovery cost, which is in the 3rd year under ideal conditions. The chosen method also has the advantages of being environmentally friendly, simple, cheap raw materials, and produces excellent $\mathrm{Cu}$ nanoparticles products. From this economic evaluation analysis, it can be concluded that this 
project is profitable with the anticipated tax changes and sales variations. So, this project is said to be feasible to run.

\section{Acknowledgement}

The authors would like to thank Dr. Eng. Asep Bayu Nandianto for providing us an exceptional guidance and suggestion through the process of writing this journal. We also thank Gabriela Chelvina Santiuly Girsang for providing assistance. 


\section{International Journal of Research and Applied Technology}

$1(1)(2021) 200-210$

Journal homepage: https://ojs.unikom.ac.id/index.php/injuratech

\section{References}

[1] Pradhan, S., Shrestha, R., \& Bhandari, K. 2020. Effect of various parameters on biosynthesis of copper nanoparticles using Citrus medica Linn (Lemon) extract and its antibacterial activity. Amrit Research Journal, 1(1), pp. 51-58.

[2] Wei, Y., Chen, S., Kowalczyk, B., Huda, S., Gray, T. P., \& Grzybowski, B. A. 2010. Synthesis of stable, low-dispersity copper nanoparticles and nanorods and their antifungal and catalytic properties. The Journal of Physical Chemistry C, 114(37), pp. 15612-15616.

[3] Sastry, A. B. S., Aamanchi, R. K., Prasad, C. S. R. L., \& Murty, B. S. 2013. Large-scale green synthesis of $\mathrm{Cu}$ nanoparticles. Environmental chemistry letters, 11(2), pp. 183187.

[4] Karthik, D. A. and Geetha, K. 2013. Synthesis of copper precursor, copper and its oxide nanoparticles by green chemical reduction method and its antimicrobial activity. Journal of Applied Pharmaceutical Science, 3(5), pp. 16-21.

[5] Padma, N., Banu, S. and Kumari, S. 2018. Studies on green synthesis of copper nanoparticles using Punica granatum. Annual Research \& Review in Biology, 23, pp. $1-10$.

[6] Amer, M. W., \& Awwad, A. M. 2021. Green synthesis of copper nanoparticles by Citrus limon fruits extract, characterization and antibacterial activity. Chem Int, 7(1), pp. 1-8.

[7] Theivasanthi, T., Alagar, M. 2011. Nano sized copper particles by electrolytic synthesis and characterizations. International Journal of Physical Sciences, 6(15), pp. 3662-3671

[8] Lee, Y., Choi, J., Lee, KJ, Stott, N. E., \& Kim, D. 2008. Large-scale synthesis of copper nanoparticles by chemically controlled reduction for applications of inkjet-printed electronics. Nanotechnology, 19(41), pp. 415604.

[9] Baco-Carles, V., Datas, L. \& Tailhades, P.H. 2011. Copper nanoparticles prepared from oxalic precursors. Nanotechnology, 2011, pp. 1-7.

[10] Solanki, J. N., Sengupta, R., \& Murthy, Z. V. P. 2010. Synthesis of copper sulphide and copper nanoparticles with microemulsion method. Solid State Sciences, 12(9), pp. 1560-1566.

[11] Giuffrida, S., Costanzo, L. L., Ventimiglia, G., \& Bongiorno, C. 2008. Photochemical synthesis of copper nanoparticles incorporated in poly(vinyl pyrrolidone). Journal of Nanoparticle Research, 10(7), pp. 1183-1192.

[12] Moniri, S., Ghoranneviss, M., Hantehzadeh, M. R., \& Asadabad, M. A. 2017. Synthesis and optical characterization of copper nanoparticles prepared by laser ablation. Bulletin of Materials Science, 40(1), pp. 37-43

[13] Tavakoli, A., Sohrabi, M. \& Kargari, A. 2007. A review of methods for synthesis of nanostructured metals with emphasis on iron compounds. Chem Pap, 61(3), pp. 151170.

[14] Lee, H. J., Lee, G., Jang, N. R., Yun, J. H., Song, J. Y., \& Kim, B. S. 2011. Biological synthesis of copper nanoparticles using plant extract. Nanotechnology, 1(1), pp. 371374.

[15] Umer, A., Naveed, S., Ramzan, N., \& Rafique, M. S. 2012. Selection of a suitable method for the synthesis of copper nanoparticles. Nano, 7(05), pp. 1230005. 
[16] Shende, S., Ingle, A. P., Gade, A., \& Rai, M. 2015. Green synthesis of copper nanoparticles by Citrus medica Linn. (Idilimbu) juice and its antimicrobial activity. World Journal of Microbiology and Biotechnology, 31(6), pp. 865-873.

[17] Nandatamadini, F., Karina, S., Nandiyanto, A. B. D., \& Ragadhita, R. 2019. Feasibility study based on economic perspective of cobalt nanoparticle synthesis with chemical reduction method. Cakra Kimia (Indonesian E-Journal of Applied Chemistry), 7(1), pp. 61-68.

[18] Nandiyanto, A. B. D., Maulana, A. C., Ragadhita, R., \& Abdullah, A. G. (2018). Economic evaluation of the production ethanol from cassava roots. In IOP Conference Series: Materials Science and Engineering (pp. 012023). IOP Publishing. 